\title{
Evaluation of the angulation of the nasal septum deviation as an anatomical variation for increased frequency of antral pseudocyst: a cone-beam computed tomography study
}

\author{
N. Laçin'1, M. Yalçın², M. Demirkol ${ }^{3}$ \\ ${ }^{1}$ Department of Oral and Maxillofacial Surgery, Faculty of Dentistry, Izmir Katip Celebi University, Izmir, Turkey \\ ${ }^{2}$ Ministry of Health, Istanbul, Turkey \\ ${ }^{3}$ Department of Oral and Maxillofacial Surgery, Faculty of Dentistry, Gaziantep University, Gaziantep, Turkey
}

[Received: 5 July 2021; Accepted: 27 October 2021; Early publication date: 16 November 2021]

\begin{abstract}
Background: The aim of the study was to determine whether degree of the nasal septum deviation (NSD) can affect the frequency of antral pseudocyst (AP) formation by cone-beam computed tomography (CBCT).

Materials and methods: This retrospective study was included 466 CBCT images. The NSD were categorised into four groups according to the degree: control group (no NSD, $\left.0^{\circ}-2^{\circ}\right)$, group $A\left(2^{\circ}-9^{\circ}\right)$, group $B\left(9^{\circ}-15^{\circ}\right)$, and group $C\left(\geq 15^{\circ}\right)$. The predictor variables were demographic factors (patient's age and gender) and anatomic factors (different degrees of nasal septum angulation). The outcome variable was presence of $A$.

Results: Of the 466 cases, 242 (51.9\%) had no NSD, 66 (14.2\%) had an angle of $2^{\circ}-9^{\circ}, 111(23.8 \%)$ had an angle of $9^{\circ}-15^{\circ}$, and $47(10.1 \%)$ had an angle of over $15^{\circ}$. The prevalence of AP was 2.04 (95\% confidence interval [CI] 1.37 to 3.03; $p=0.001$ ) times higher in the presence of NSD. Significant increases in presence of AP occurred with NSD in group $A$ (2.37 times higher; $p=0.003$ ) and group $B$ (2.07 times higher; $p=0.003$ ) compared to control by univariate analysis.

Conclusions: Although there is no sufficient evidence to suggest that NSD is a definitive aetiological factor for AP development, our findings indicated that NSD increased the risk of AP formation. (Folia Morphol 2023; 82, 1: 158-165)
\end{abstract}

Key words: nasal septum, deviation, antral pseudocyst

\section{INTRODUCTION}

Antral pseudocysts (APs) are radiopaque, domeshaped lesions that do not contain a true epithelial lining and are composed of a serous exudate. APs are predominantly located in the maxillary bone and associated with the Schneiderian membrane [37]. These pathological entities are asymptomatic and can be detected during radiological examination particularly by plain radiography and/or cone-beam computed tomography (CBCT). APs are considered to be associated with allergic reactions, humidity, temperature, trauma, smoking, odontogenic infection, although its pathogenesis remains controversial $[7,8,26,29]$. In the sinus elevation procedures through crestal or lateral approach, AP can also be caused by the perforation, trauma and infection of

Address for correspondence: M. Yalçın, DDS, Istanbul Kent University, Faculty of Dentistry, Department of Oral and Maxillofacial Surgery, Istanbul, Turkey, tel: +90 0553 6506065, e-mail: myalcin.omfs@gmail.com

This article is available in open access under Creative Common Attribution-Non-Commercial-No Derivatives 4.0 International (CC BY-NC-ND 4.0) license, allowing to download articles and share them with others as long as they credit the authors and the publisher, but without permission to change them in any way or use them commercially. 
the Schneiderian membrane. AP might be unilateral or bilateral in the maxillary bone and the dimension of AP might increase gradually, remain the same, or decrease gradually $[16,38,39]$. AP cannot disrupt the integrity of the cortical plate of the maxillary sinus and of the Schneiderian membrane [16, 39].

Nasal airflow directly affects the development of craniomaxillofacial bones and paranasal sinuses [22]. Obliteration of the nasal passage caused by nasal septum deviation (NSD) prevents optimal nasal breathing and also results in mouth breathing [4]. Nasal septum is defined as a midline structure of the nasal cavity which divides the nasal cavity into halves and supports the external nose structurally [13]. Nasal septum consists of cartilaginous (anteriorly, quadrangular cartilage), bony (posteriorly, vomer and perpendicular plate of the ethmoid bone) and membranous components [13]. NSD is an anatomic variation that affects approximately $80 \%$ of adults $[36,43]$. In the literature, there are various classifications of NSDs [5, 19]. Cerkes [9] defined five main nasal septum deviation, named as caudal septal deviation, anteroposterior C-shaped deviation, cephalocaudal C-shaped deviation, anteroposterior S-shaped deviation and cephalocaudal S-shaped deviation. Guyuron et al. [19] reported that the most frequent type of NSD was characterised by an inclined septum.

Maxillary sinus pneumatisation and airway obstruction in the nose are predisposing factors for pathologies in the maxillary sinus [35]. The maxillary sinus volume might change according to the capacity of the nasal airflow $[15,30]$. NSD, concha bullosa, and ostium obstruction might alter the pneumatisation of the maxillary sinus, thereby leading to the thickening of the maxillary sinus membrane and chronic sinusitis [23]. NSD is also an aetiological factor affecting the nasal airway and pneumatisation of the maxillary sinus [23].

Although possible aetiological factors in the development of AP have been reported in the literature, no study evaluating the relationship between NSD and AP development has been identified. We aimed to investigate whether the presence and degree of NSD has an effect on the development of AP by using CBCT.

\section{MATERIALS AND METHODS}

\section{Study sample}

Initially, seven hundred CBCT scans obtained between January 2016 and July 2018 and retrieved from the archives of the Faculty of Dentistry, Izmir Katip Çelebi University were included. CBCT scan were taken for orthodontic treatment, oral and maxillofacial examination and dental implant treatment. The following inclusion criteria were applied: patients older than 18 years, nasal area and both maxillary sinuses entirely visible on the scan with AP present or absent. Exclusion criteria included inadequate scan quality, impacted teeth in the maxillary sinus, nasal and antral sinus infection, cyst and tumour associated with maxillary sinus and/or nasal structure, pseudocyst related to odontogenic infection, age under 18 years, S-shaped septum deviation, multifaceted nasal septum deviation, concha bullosa, previous maxillofacial and/or paranasal surgery, and maxillofacial trauma. After detailed examination, a total of 466 patients with CBCT scan (236 male, 230 female) met our inclusion criteria.

The study was approved by the Ethics Committee of Izmir Katip Çelebi University. (Approval No.: 230), and the study protocol was conducted in accordance with the Helsinki Declaration 1975 as revised in 2000.

\section{CBCT image acquisition, evaluation of the antral pseudocyst and nasal septum}

All the images were obtained using a CBCT device (NewTom 5G CBCT machine, QR s.r.l., Verona, Italy). The exposure parameters were as follows: $110 \mathrm{kVp}$, 1-20 mA, with $15 \times 12 \mathrm{~cm}$ field of view and resolution mode (voxel size $0.2 \mathrm{~mm}$ ). The maxillary CBCT scans were obtained from the level of the maxillary teeth crown to the top of the orbit. All CBCT images were evaluated by the same experienced surgeons (NL and MY) on a desktop UltraSharp LED TFT 24-inch monitor (Dell Inc., Round Rock, TX, USA) with appropriate background lighting.

Antral pseudocysts were defined as unilacunar, dome-shaped, radiopaque lesions with no bone resorption on the wall of the maxillary sinus, particularly on the floor of the sinus (Fig. 1) $[1,8,17,20,24,25$, $28,39,44]$. AP location was classified as right, left and bilateral based on the location of the lesions in the maxillary sinus.

The location of the concavity was determined based on the direction of the deviation [2]. The NSD angle was measured between the two lines drawn on the coronal section of CBCT with the first line drawn from the crista galli to the anterior nasal spine and the second line drawn from the crista galli to the most prominent point of the deviation 


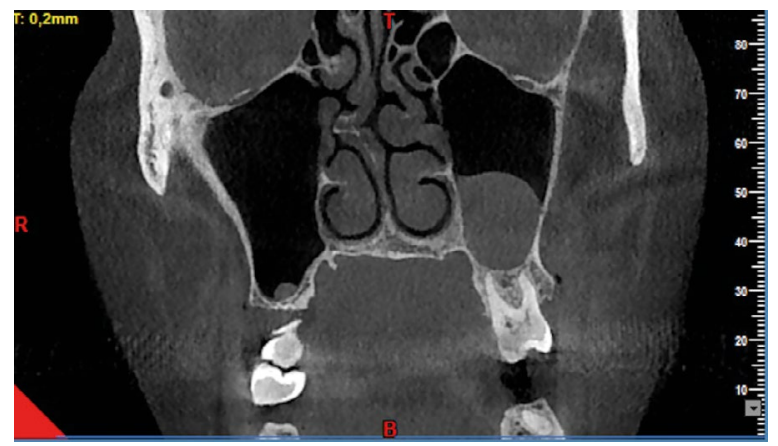

Figure 1. Radiographic appearance of antral pseudocysts in the maxillary sinus.

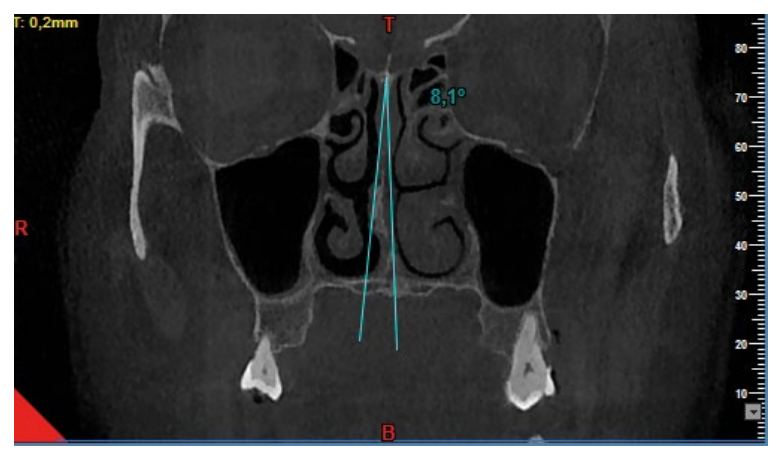

Figure 2. The nasal septum deviation angle was measured between the two lines drawn on the coronal section of cone-beam computed tomography, with the first line drawn from the crista galli to the anterior nasal spine and the second line drawn from the crista galli to the most prominent point of the deviation.

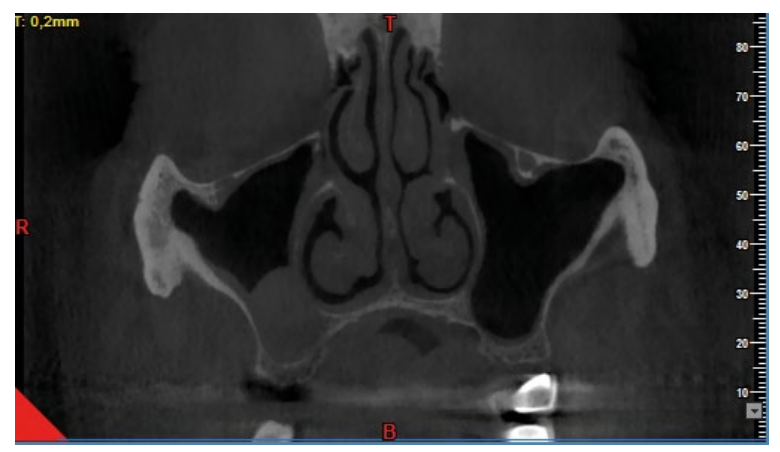

Figure 3. Radiographic appearance of straight nasal septum.

(Fig. 2) [2]. Patients were divided into four groups based on the degree of NSD: i) control group (no NSD, $0^{\circ}<\mathrm{NSD} \leq 2^{\circ}$ ), ii) group $A$ (mild, $2^{\circ}<\mathrm{NSD}$ $\leq 9^{\circ}$ ), iii) group $B\left(\right.$ moderate, $\left.9^{\circ}<N S D \leq 15^{\circ}\right)$, and iv) group $C$ (severe, NSD $\geq 15^{\circ}$ ) [43]. Directions of NSD were divided into three groups: i) straight nasal septum (control group, $0^{\circ}<\mathrm{NSD} \leq 2^{\circ}$ ), ii) nasal septum deviated to the right, and iii) nasal septum deviated to the left. These measurements were

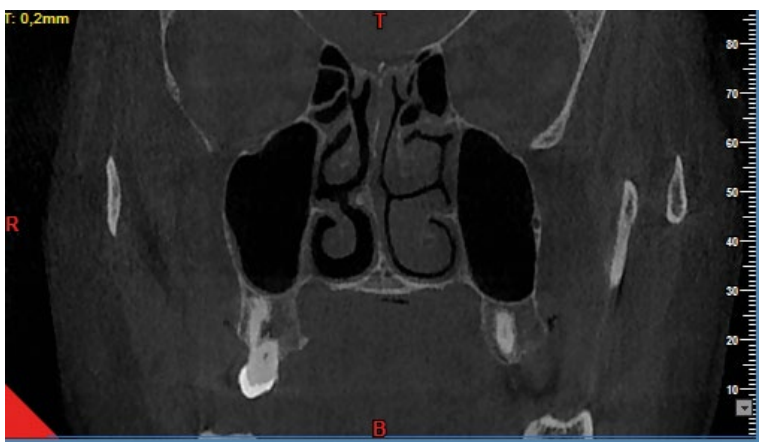

Figure 4. Radiographic appearance of the nasal septum deviated to the right.

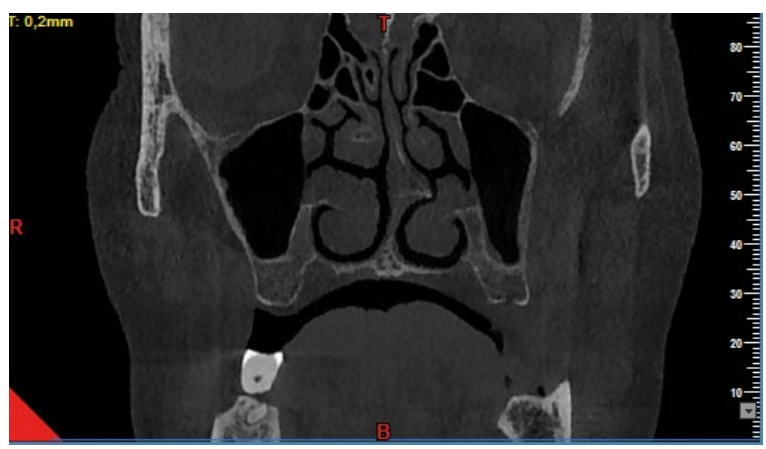

Figure 5. Radiographic appearance of the nasal septum deviated to the left.

made in the coronal view and are demonstrated in Figures 3, 4 and 5.

\section{Statistical analysis}

Statistical analyses were performed using SPSS for Windows version 22.0 (IBM Corp., Armonk, NY, USA). Binary and multinomial logistic regression analyses were used to estimate the odds ratio (OR) and $95 \%$ confidence interval $(\mathrm{Cl})$. Gender and age were included in the models to adjust their effects on the dependent variable. Descriptive statistics were expressed as frequencies (n), percentages (\%), and mean \pm standard deviation (SD). Intra-operator reliability for each measurement was assessed using the intra-class correlation coefficient (ICC), with an interval of at least 3 weeks between measurements, which yielded a $98 \%$ agreement rate. The predictor variables were demographic factors (patient's age and gender) and anatomic factors (different degrees of nasal septum angulation). The outcome variable was presence of AP. The relation between predictors and outcome variable was analysed using binary and multinomial logistic regression analyses, with statistical significance set at a $p$ value less than 0.05 . 
Table 1. Data of the mean age and nasal septum deviation (NSD) angle

\begin{tabular}{lccccc}
\hline & Number of patients & Minimum & Maximum & Mean & Standard deviation \\
\hline Age & 466 & 18 & 83 & 40.53 & 18.170 \\
NSD angle & 466 & .0 & 33.9 & 5.819 & 6.9304 \\
\hline
\end{tabular}

Table 2. Descriptive statistics for 224 cases with nasal septum deviation (NSD)

\begin{tabular}{lccccc}
\hline & Number & Minimum & Maximum & Mean & Standard deviation \\
\hline NSD angle & 224 & 4.6 & 33.9 & 12.106 & 4.8689 \\
\hline
\end{tabular}

Table 3. Distribution of cases according to the gender, antral pseudocysts (AP) and nasal septum deviation (NSD)

\begin{tabular}{llcc}
\hline \multirow{4}{*}{ Gender } & & N & $\%$ \\
\hline \multirow{4}{*}{ AP in maxillary sinus } & Male & 236 & 50.6 \\
& Female & 230 & 49.4 \\
& Absence & 316 & 67.8 \\
& Right & 55 & 11.8 \\
& Left & 48 & 10.3 \\
& Bilateral & 47 & 10.1 \\
& Absence & 242 & 51.9 \\
& $2^{\circ}<$ NSD $<9^{\circ}$ & 66 & 14.2 \\
& $9^{\circ} \leq \mathrm{NSD}<15^{\circ}$ & 111 & 23.8 \\
& NSD $\geq 15^{\circ}$ & 47 & 10.1 \\
\hline
\end{tabular}

\section{RESULTS}

According to the ICC test, the concordance index was greater than 0.98 , indicating high intra-examiner concordance.

The 466 patients included $50.6 \%(n=236)$ men and $49.4 \%$ ( $n=230$ ) women with a mean age of $40.53 \pm 18.17$ (range: $13-83$ ) years and mean NSD angle $5.81 \pm 6.93$ (Table 1). A straight nasal septum (control group) was detected in 242 (51.9\%) images and NSD was detected in 224 (48.1\%) images (mean NSD angle, $12.10 \pm 4.86$ ) as shown in Table 2. Of the 224 NSD cases, 66 (14.2\%) cases had an NSD angle of $2^{\circ}-9^{\circ}, 111(23.8 \%)$ of them had an angle of $9^{\circ}-15^{\circ}$, and $47(10.1 \%)$ of them had an angle of over $15^{\circ}$ (Table 3). APs were detected in 150 (32.2\%) cases, among whom the lesion was localised on the right side in $55(11.8 \%)$, on the left side in $48(10.3 \%)$, and on both sides in $47(10.1 \%)$ cases (Table 3$)$. Distribution of the AP was shown in Table 4.

Binary logistic regression analysis indicated that the prevalence of AP was $1.82(95 \% \mathrm{Cl}$; range: $1.23-$ $-2.7)$ times higher in men than in women $(p=0.003)$. Moreover, the prevalence of AP was 2.04 (range:
1.37-3.03) times higher in the presence of NSD than in the absence of NSD ( $p=0.001)$ and the age- and gender-adjusted OR was 1.97 (95\% Cl: 1.32-2.93; $\mathrm{p}=0.001)$. The prevalence of AP was $2.54(95 \% \mathrm{Cl}$ : 1.60-4.03; $p=0.001)$ times higher in the right maxillary sinus with NSD compared to the control group and the age- and gender-adjusted OR was 2.44 (95\% Cl: 1.52-3.89; $p=0.001$ ). However, no significant difference was found between the prevalence of AP in the left maxillary sinus and in the control group ( $p=0.069$ ). On the other hand, the prevalence of AP was 2.37 times higher in group $A$ and 2.07 times higher in group $B$ compared to the control group and the age- and gender-adjusted results were statistically significant as well ( $p=0.003$ and $p=0.005$, respectively). Nevertheless, no significant difference was found between group $C$ and the control group $(p=0.190)$ (Table 5).

\section{DISCUSSION}

Aetiological factors of pathological entities or anatomical variations in the maxillary sinus typically include upper respiratory tract infection, trauma, congenital deformities, odontogenic infection/cyst/ /tumour, adenotonsillar hypertrophy, and chronic nasal airway obstruction $[3,11]$. Some of these entities might be symptomatic such as acute sinusitis, odontogenic cyst while some of them might be asymptomatic such as mucocele, pseudocyst, antral polyps, and mucous retention cyst. The pathologies in the maxillary sinus are generally detected incidentally in routine radiographic and/or clinical examination.

The CBCT enables a three-dimensional examination for the assessment of the anatomic structure and pathologies of the maxillofacial region, thereby allowing a definitive diagnosis. Three-dimensional CBCT images were used in the current study for the detection of the NSD type, measurement of the NSD 
Table 4. Distribution of the antral pseudocysts according to the nasal septum deviation (NSD), gender, direction of the NSD and NSD angle

\begin{tabular}{|c|c|c|c|c|c|c|c|c|c|}
\hline & \multicolumn{8}{|c|}{ Location of antral pseudocysts } & \multirow[t]{3}{*}{ P-value } \\
\hline & \multicolumn{2}{|c|}{ Right } & \multicolumn{2}{|c|}{ Left } & \multicolumn{2}{|c|}{ Bilateral } & \multicolumn{2}{|c|}{ Absence } & \\
\hline & $\mathbf{N}$ & $\%$ & $\mathbf{N}$ & $\%$ & $\mathbf{N}$ & $\%$ & $\mathbf{N}$ & $\%$ & \\
\hline NSD & & & & & & & & & 0.05 \\
\hline Absence & 23 & 41.8 & 18 & 37.5 & 19 & 40.4 & 182 & 57.6 & \\
\hline Presence & 32 & 58.2 & 30 & 62.5 & 28 & 59.6 & 134 & 42.4 & \\
\hline Gender & & & & & & & & & 0.007 \\
\hline Male & 36 & 65.5 & 24 & 50 & 31 & 66 & 145 & 45.9 & \\
\hline Female & 19 & 34.5 & 24 & 50 & 16 & 34 & 171 & 54.1 & \\
\hline Direction of NSD & & & & & & & & & 0.009 \\
\hline Straight & 23 & 41.8 & 18 & 37.5 & 19 & 40.4 & 183 & 57.9 & \\
\hline Right & 18 & 32.7 & 19 & 39.6 & 18 & 38.3 & 66 & 20.9 & \\
\hline Left & 14 & 25.5 & 11 & 22.9 & 10 & 21.3 & 67 & 21.2 & \\
\hline NSD angle & & & & & & & & & 0.011 \\
\hline Absence & 23 & 41.8 & 18 & 37.5 & 19 & 40.4 & 182 & 57.6 & \\
\hline $2^{\circ}<\mathrm{NSD}<9^{\circ}$ & 13 & 23.6 & 7 & 14.6 & 9 & 19.1 & 37 & 11.7 & \\
\hline $9^{\circ} \leq \mathrm{NSD}<15^{\circ}$ & 13 & 23.6 & 20 & 41.7 & 12 & 25.5 & 66 & 20.9 & \\
\hline $\mathrm{NSD} \geq 15^{\circ}$ & 6 & 10.9 & 3 & 6.3 & 7 & 14.9 & 31 & 9.8 & \\
\hline
\end{tabular}

Table 5. Multivariate analysis of factors associated with antral pseudocysts

\begin{tabular}{|c|c|c|c|c|c|c|c|c|}
\hline \multirow[t]{3}{*}{ Variables } & \multicolumn{4}{|c|}{ Antral pseudocysts } & & & & \\
\hline & \multirow{2}{*}{\multicolumn{2}{|c|}{$\begin{array}{c}\text { Presence }(n=150) \\
\text { Mean } \pm \text { SD }\end{array}$}} & \multirow{2}{*}{\multicolumn{2}{|c|}{$\begin{array}{c}\text { Absence }(\mathrm{n}=\mathbf{3 1 6}) \\
\text { Mean } \pm \text { SD }\end{array}$}} & \multicolumn{2}{|c|}{ Univariate } & \multicolumn{2}{|c|}{ Age and gender adjusted results } \\
\hline & & & & & OR [95\% Cl] & $\mathbf{P}$ & OR [95\% Cl] & $\mathbf{P}$ \\
\hline \multirow[t]{2}{*}{ Age } & \multicolumn{2}{|c|}{$42.14 \pm 16.04$} & \multicolumn{2}{|c|}{$39.77 \pm 19.08$} & $1.01[0.97-1.02]$ & 0.188 & & \\
\hline & $\mathbf{N}$ & $\%$ & $\mathbf{N}$ & $\%$ & & & & \\
\hline \multicolumn{9}{|l|}{ Gender } \\
\hline Male & 91 & 60.7 & 145 & 45.9 & $1.82[1.23-2.7]$ & $0.003^{*}$ & & \\
\hline Female & 59 & 39.3 & 171 & 54.1 & 1 (reference) & & & \\
\hline \multicolumn{9}{|l|}{ Direction of NSD } \\
\hline Straight & 60 & 40.0 & 183 & 57.9 & 1 (reference) & & 1 (reference) & \\
\hline Right & 55 & 36.7 & 66 & 20.9 & $2.54[1.60-4.03]$ & $0.001 *$ & $2.44[1.52-3.89]$ & $0.001 *$ \\
\hline Left & 35 & 23.3 & 67 & 21.2 & $1.59[0.96-2.63]$ & 0.069 & $1.56[0.94-2.59]$ & 0.084 \\
\hline \multicolumn{9}{|l|}{ NSD } \\
\hline Presence & 90 & 60 & 134 & 42.4 & 2.04 [1.37-3.03] & $0.001 *$ & $1.97[1.32-2.93]$ & $0.001 *$ \\
\hline Absence & 60 & 40 & 182 & 57.6 & 1 (reference) & & 1 (reference) & \\
\hline \multicolumn{9}{|l|}{ NSD angle } \\
\hline Absence & 60 & 40.0 & 182 & 57.6 & 1 (reference) & & 1 (reference) & \\
\hline $2^{\circ}<\mathrm{NSD}<9^{\circ}$ & 29 & 19.3 & 37 & 11.7 & 2.37 [1.35-4.19] & $0.003^{*}$ & 2.39 [1.35-4.26] & $0.003^{*}$ \\
\hline $9^{\circ} \leq \mathrm{NSD}<15^{\circ}$ & 45 & 30.0 & 66 & 20.9 & $2.07[1.28-3.37]$ & $0.003^{*}$ & 2.01 [1.24-3.25] & $0.005^{*}$ \\
\hline $\mathrm{NSD} \geq 15^{\circ}$ & 16 & 10.7 & 31 & 9.8 & $1.57[0.80-3.06]$ & 0.190 & $1.41[0.71-2.78]$ & 0.324 \\
\hline
\end{tabular}

*Significant at the 0.05 level; Binary logistic regression model; $\mathrm{Cl}$ — confidence interval; NSD — nasal septum deviation; OR — odds ratio; SD — standard deviation

angle, detection of $\mathrm{AP}$, and the evaluation of the maxillofacial structure.
Previous studies indicated that the nasal obstruction and impaired intranasal airflow caused by NSD 
have an adverse effect on mucociliary activity and the resulting ciliary loss has been shown to increase the incidence of rhinosinusitis [14, 31, 32, 42]. However, although the relationship between NSD and chronic diseases of the sinus has been documented, an exact positive correlation has not yet been established due to inconsistent findings presented by the studies. In a 2009 study, Polat and Dostbil [34] evaluated patients with NSD using rhinoscintigraphy and reported that the administration of septoplasty improved the reduced nasal mucociliary transport rate. Although there have been several studies supporting this finding, Greguric et al. [18] and Collet et al. [10] reported that they found no definitive role of NSD in the pathogenesis of chronic rhinosinusitis [31]. Similarly, Yasan et al. [46] revealed that the mild-to-moderate septal deviation was not a risk factor for chronic sinusitis and only severe septal deviation was found to be a risk factor for the disease. In a confirmatory manner, a systematic review conducted in 2010 found a significant relationship between a septal deviation of $>10^{\circ}$ and rhinosinusitis [31]. Although the studies abovementioned have investigated rhinosinusitis, the present study examined the possible effect of NSD on AP associated with inflammatory factors and a comparison was only made with the studies abovementioned since there are a limited number of studies reporting on the relationship between NSD and AP.

In our study, 90 (60\%) of the patients were detected with NSD and Binary logistic regression analysis indicated that the prevalence of AP was 2.04 (range: 1.37-3.03) times higher in patients with NSD than in patients without NSD $(p=0.001)$. Additionally, the prevalence of AP was 2.37 (range: 1.35-4.19) times higher in group $A\left(2^{\circ}-9^{\circ}\right)$ and 2.07 (range: 1.28-3.37) times higher in group $B\left(9^{\circ}-15^{\circ}\right)$ compared to the control group $\left(0^{\circ}-2^{\circ}\right)(p=0.003$ for both). However, although no significant difference was found between group $C\left(\geq 15^{\circ}\right)$ and the control group with regard to AP prevalence $(p=0.190)$, this prevalence was 1.41 (range: $0.71-2.78$ ) times higher in group $C$ compared to the control group. These findings are rather consistent with the results of the study by Orlandi [31] who found a significant relationship between a septal deviation of $>10^{\circ}$ and rhinosinusitis.

On the other hand, rhinosinusitis, particularly chronic rhinosinusitis, is considered to be associated with allergies, bacteria, viruses, biofilms, osteitis, superantigens, immunological dysregulation, and gastroesophageal reflux $[6,27]$. It has also been re- ported that a single independent factor could not be held responsible and that there could be multiple factors leading to the development of rhinosinusitis $[6,27]$. Additionally, although NSD is known to cause ostiomeatal complex narrowing and thereby to aggravate inflammation, the contralateral inflammation in NSD has been reported to be associated with different aetiologies [33]. Perloff et al. [33] suggested that the inflammation spread to the contralateral side through the Haversian system and another hypothesis posited that contralateral inflammation was caused by the nasal secretions pushed into the sinus during nose blowing. Some other studies indicated that the increased airflow on the side contralateral to the deviated septum and the turbulence in the medial meatus lead to ciliary loss in the maxillary sinus and also increase inflammation on both sides [21, 40]. Moreover, NSD has also been radiologically shown to be associated with the presence of contralateral concha bullosa [14, 41].

Antral pseudocysts have been reported to be associated with environmental factors including allergic reactions, smoking, trauma, changes in the air temperature, and humidity $[7,8,26,29]$. A recent study by de Carvalho et al. [12] reported a significant relationship between the presence of AP and greater height of the maxillary sinus ostium. Another study that was conducted by the two authors of the present study and awaits publication revealed that AP could be associated with the masticatory forces transmitted to the sinus membrane through the protruded healthy maxillary molar roots penetrated into the maxillary sinus [45].

Given that NSD alone could not be held responsible for the development of rhinosinusitis, we consider that NSD alone could not be held responsible for the development of AP as well. This hypothesis could be supported by our finding that indicated that AP was detected in patients with NSD and on the non-deviated (unaffected) side as well, considering that it would be more reasonable to expect that the risk of inflammation on the deviated side would be relatively higher [31]. Accordingly, based on the inflammatory effect of NSD in the pathogenesis of rhinosinusitis reported in the literature, it could be asserted that NSD could have an effective role in the aetiopathogenesis of $A P$.

Our study was limited in several ways. First, the study only included the clinical symptoms of NSD and the patients with right- or left-side deviation due to 
its nature. Accordingly, it did not include the other NSD types and thus included no evaluation on the effect of other NSD types. Secondly, no evaluation was performed on the relationship between AP and the pathologies that could be associated with nasal airway obstruction other than NSD.

\section{CONCLUSIONS}

Although there is no sufficient evidence to suggest that NSD is a definitive aetiological factor for AP development, our findings indicated that NSD increased the risk of AP formation.

\section{Conflict of interest: None declared}

\section{REFERENCES}

1. Allard RH, van der Kwast WA, van der Waal I. Mucosal antral cysts. Review of the literature and report of a radiographic survey. Oral Surg Oral Med Oral Pathol. 1981; 51(1): 2-9, doi: 10.1016/0030-4220(81)90118-3, indexed in Pubmed: 7007951.

2. Al-Rawi NH, Uthman AT, Abdulhameed E, et al. Concha bullosa, nasal septal deviation, and their impacts on maxillary sinus volume among Emirati people: A cone-beam computed tomography study. Imaging Sci Dent. 2019; 49(1): 45-51, doi: 10.5624/isd.2019.49.1.45, indexed in Pubmed: 30941287.

3. Apuhan T, Yıldırım YS, Özaslan H. The developmental relation between adenoid tissue and paranasal sinus volumes in 3-dimensional computed tomography assessment. Otolaryngol Head Neck Surg. 2011; 144(6): 964-971, doi: 10.1177/0194599811399712, indexed in Pubmed: 21493325.

4. Ballanti F, Baldini A, Ranieri S, et al. Is there a correlation between nasal septum deviation and maxillary transversal deficiency? A retrospective study on prepubertal subjects. Int J Pediatr Otorhinolaryngol. 2016; 83: 109-112, doi: 10.1016/j.ijporl.2016.01.036, indexed in Pubmed: 26968064.

5. Baumann I, Baumann H. A new classification of septal deviations. Rhinology. 2007; 45(3): 220-223, indexed in Pubmed: 17956023.

6. Benninger MS, Ferguson BJ, Hadley JA, et al. Adult chronic rhinosinusitis: definitions, diagnosis, epidemiology, and pathophysiology. Otolaryngol Head Neck Surg. 2003; 129(3 Suppl): S1-32, doi: 10.1016/s0194-5998(03)013974, indexed in Pubmed: 12958561.

7. Carter LC, Calamel A, Haller A, et al. Seasonal variation in maxillary antral pseudocysts in a general clinic population. Dentomaxillofac Radiol. 1998; 27(1): 22-24, doi: 10.1038/ sj.dmfr.4600311, indexed in Pubmed: 9482018.

8. Casamassimo PS, Lilly GE. Mucosal cysts of the maxillary sinus: a clinical and radiographic study. Oral Surg Oral Med Oral Pathol. 1980; 50(3): 282-286, doi: 10.1016/00304220(80)90385-0, indexed in Pubmed: 6932003.

9. Cerkes N. The crooked nose: principles of treatment. Aesthet Surg J. 2011; 31(2): 241-257, doi:
10.1177/1090820X10394167, indexed in Pubmed: 21317122

10. Collet S, Bertrand B, Cornu S, et al. Is septal deviation a risk factor for chronic sinusitis? Review of literature. Acta Otorhinolaryngol Belg. 2001; 55(4): 299-304, indexed in Pubmed: 11859650.

11. Cooper BC. Nasorespiratory function and orofacial development. Otolaryngol Clin North Am. 1989; 22(2): 413-441, indexed in Pubmed: 2664660.

12. de Carvalho AB, Ferreira Costa AL, Fuziy $A$, et al. Investigation on the relationship of dimensions of the maxillary sinus drainage system with the presence of sinusopathies: a cone beam computed tomography study. Arch Oral Biol. 2018; 94: 78-83, doi: 10.1016/j.archoralbio.2018.06.021, indexed in Pubmed: 29990588.

13. Delaney SW. Evolution of the septoplasty: maximizing functional and aesthetic outcomes in nasal surgery. MJ Otol. 2018; 1(1): 004.

14. Elahi M, Frenkiel S. Septal deviation and chronic sinus disease. Am J Rhinol. 2018; 14(3): 175-180, doi: 10.2500/105065800782102735.

15. Gencer ZK, Ozkırıs M, Okur A, et al. The effect of nasal septal deviation on maxillary sinus volumes and development of maxillary sinusitis. Eur Arch Otorhinolaryngol. 2013; 270(12): 3069-3073, doi: 10.1007/s00405-013-2435-y, indexed in Pubmed: 23512432.

16. Giotakis El, Weber RK. Cysts of the maxillary sinus: a literature review. Int Forum Allergy Rhinol. 2013; 3(9): 766-771, doi: 10.1002/alr.21177, indexed in Pubmed: 23677671.

17. Gothberg KA, Little JW, King DR, et al. A clinical study of cysts arising from mucosa of the maxillary sinus. Oral Surg Oral Med Oral Pathol. 1976; 41(1): 52-58, doi: 10.1016/0030-4220(76)90251-6, indexed in Pubmed: 1061037.

18. Gregurić T, Baudoin T, Tomljenović D, et al. Relationship between nasal septal deformity, symptoms and disease severity in chronic rhinosinusitis. Eur Arch Otorhinolaryngol. 2016; 273(3): 671-677, doi: 10.1007/s00405-015-3615-8, indexed in Pubmed: 25827442.

19. Guyuron B, Uzzo C, Scull H. A practical classification of septonasal deviation and an effective guide to septal surgery. Plast Reconstr Surg. 1999; 104(7): 2202-2209, doi: 10.1097/00006534-199912000-00041.

20. Harar RPS, Chadha NK, Rogers G. Are maxillary mucosal cysts a manifestation of inflammatory sinus disease? J Laryngol Otol. 2007; 121(8): 751-754, doi: 10.1017/ S0022215107005634, indexed in Pubmed: 17250779.

21. Jang YJu, Myong NH, Park KH, et al. Mucociliary transport and histologic characteristics of the mucosa of deviated nasal septum. Arch Otolaryngol Head Neck Surg. 2002; 128(4): 421-424, doi: 10.1001/archotol.128.4.421, indexed in Pubmed: 11926918.

22. Klein JC. Nasal respiratory function and craniofacial growth. Arch Otolaryngol Head Neck Surg. 1986; 112(8): 843-849, doi: 10.1001/archotol.1986.03780080043009, indexed in Pubmed: 3718688.

23. Kucybała I, Janik KA, Ciuk $S$, et al. Nasal septal deviation and concha bullosa: do they have an impact on maxillary sinus volumes and prevalence of maxillary sinusitis? Pol J Radiol. 2017; 82: 126-133, doi: 10.12659/PJR.900634, indexed in Pubmed: 28348652. 
24. Lacin N, Tatar B. Evaluation of the frequency of mucous retention cysts in the maxillary sinus in a Turkish population using cone-beam computed tomography. Makara J Health Res. 2019; 23(2): 1, doi: 10.7454/msk.v23i2.10711.

25. Lilly GE, Cutcher JL, Steiner M. Spherical shadows within the maxillary antrium. J Oral Med. 1968; 23(1): 19-21, indexed in Pubmed: 5238722.

26. Mafee MF, Valvassori GE, Becker M. Imaging of the Head and Neck. New York, Stuttgart, Thieme 2005.

27. Meltzer EO, Hamilos DL, Hadley JA, et al. Rhinosinusitis: establishing definitions for clinical research and patient care. J Allergy Clin Immunol. 2004; 114(6 Suppl): 155-212, doi: 10.1016/j.jaci.2004.09.029, indexed in Pubmed: 15577865.

28. Myall RW, Eastep PB, Silver JG. Mucous retention cysts of the maxillary antrum. J Am Dent Assoc. 1974; 89(6): 1338-1342, doi: 10.14219/jada.archive.1974.0612, indexed in Pubmed: 4529984.

29. Nunes CA, Guedes OA, Alencar AH, et al. Evaluation of periapical lesions and their association with maxillary sinus abnormalities on cone-beam computed tomographic images. J Endod. 2016; 42(1): 42-46, doi: 10.1016/j. joen.2015.09.014, indexed in Pubmed: 26521148.

30. Orhan I, Ormeci T, Aydin S, et al. Morphometric analysis of the maxillary sinus in patients with nasal septum deviation. Eur Arch Otorhinolaryngol. 2014; 271(4): 727-732, doi: 10.1007/s00405-013-2617-7, indexed in Pubmed: 23832260.

31. Orlandi RR. A systematic analysis of septal deviation associated with rhinosinusitis. Laryngoscope. 2010; 120(8): 1687-1695, doi: 10.1002/lary.20992, indexed in Pubmed: 20564661.

32. Passàli D, Ferri R, Becchini G, et al. Alterations of nasal mucociliary transport in patients with hypertrophy of the inferior turbinates, deviations of the nasal septum and chronic sinusitis. Eur Arch Otorhinolaryngol. 1999; 256(7): 335-337, doi: 10.1007/s004050050158, indexed in Pubmed: 10473825.

33. Perloff JR, Gannon FH, Bolger WE, et al. Bone involvement in sinusitis: an apparent pathway for the spread of disease. Laryngoscope. 2000; 110(12): 2095-2099, doi: 10.1097/00005537-200012000-00023, indexed in Pubmed: 11129028.

34. Polat C, Dostbil Z. Evaluation of the nasal mucociliary transport rate by rhinoscintigraphy before and after surgery in patients with deviated nasal septum. Eur Arch Otorhinolaryngol. 2010; 267(4): 529-535, doi: 10.1007/ s00405-009-1116-3, indexed in Pubmed: 19816701.

35. Poorey VK, Gupta N. Endoscopic and computed tomographic evaluation of influence of nasal septal deviation on lateral wall of nose and its relation to sinus diseases. Indian J Otolaryngol Head Neck Surg. 2014; 66(3):
330-335, doi: 10.1007/s12070-014-0726-2, indexed in Pubmed: 25032124.

36. Roblin DG, Eccles R. What, if any, is the value of septal surgery? Clin Otolaryngol Allied Sci. 2002; 27(2): 77-80, doi: 10.1046/j.1365-2273.2002.00531.x, indexed in Pubmed: 11994109.

37. Rodrigues C, Arruda J, Silva L, et al. Antral pseudocysts of the maxillary sinus: relationship between radiographic and clinical features. JORDI Journal of Oral Diagnosis. 2017; 2: 1-7, doi: 10.5935/2525-5711.20170042.

38. Rodrigues $C D$, Freire GF, Silva LB, et al. Prevalence and risk factors of mucous retention cysts in a Brazilian population. Dentomaxillofac Radiol. 2009; 38(7): 480-483, doi: 10.1259/dmfr/48774803, indexed in Pubmed: 19767520.

39. Ruprecht A, Batniji S, El-Neweihi E. Mucous retention cyst of the maxillary sinus. Oral Surg Oral Med Oral Pathol. 1986; 62(6): 728-731, doi: 10.1016/0030-4220(86)902719.

40. Shin SH, Heo WW. Effects of unilateral naris closure on the nasal and maxillary sinus mucosa in rabbit. Auris Nasus Larynx. 2005; 32(2): 139-143, doi: 10.1016/j. anl.2005.01.015, indexed in Pubmed: 15917170.

41. Stallman JS, Lobo JN, Som PM. The incidence of concha bullosa and its relationship to nasal septal deviation and paranasal sinus disease. AJNR Am J Neuroradiol. 2004; 25(9): 1613-1618, indexed in Pubmed: 15502150.

42. Tawakir K, Yilmaz T, Surucu S, et al. Scanning electron microscopy of ciliae and saccharine test for ciliary function in septal deviations. Laryngoscope. 2006; 116(4): 586-590, doi: 10.1097/01.MLG.0000205608.50526.28, indexed in Pubmed: 16585863.

43. van Egmond MM, Rovers MM, Hendriks CTM, et al. Effectiveness of septoplasty versus non-surgical management for nasal obstruction due to a deviated nasal septum in adults: study protocol for a randomized controlled trial. Trials. 2015; 16: 500, doi: 10.1186/s13063-015-1031-4, indexed in Pubmed: 26537948.

44. Wang JH, Jang YJu, Lee BJ. Natural course of retention cysts of the maxillary sinus: long-term follow-up results. Laryngoscope. 2007; 117(2): 341-344, doi: 10.1097/01. mlg.0000250777.52882.7a, indexed in Pubmed: 17277631.

45. Yalçın $\mathrm{M}$, Laçin $\mathrm{N}$. Is the relationship of maxillary molar roots to the floor of the maxillary sinus associated with antral pseudocysts? A retrospective study using cone beam computed tomography. Oral Surg Oral Med Oral Pathol Oral Radiol. 2020; 130(5): 574-582, doi: 10.1016/j. oooo.2020.05.003, indexed in Pubmed: 32546427.

46. Yasan H, Doğru H, Baykal B, et al. What is the relationship between chronic sinus disease and isolated nasal septal deviation? Otolaryngol Head Neck Surg. 2005; 133(2): 190-193, doi: 10.1016/j.otohns.2005.04.013, indexed in Pubmed: 16087012. 